\title{
Introduction: Edible Alterities, Perspectives from
}

\section{La Francophonie}

\section{Angela Giovanangeli and Julie Robert, University of Technology, Sydney}

This project began, as many do, in the company of a good friend over a meal. This particular meal, however, was being eaten at a newly opened vegan establishment in Sydney. After the plates had been cleared, the chef emerged into the near empty dining room and apologised for having no desserts to offer because he had not yet mastered the art of vegan baking. As he waxed on describing his unsuccessful attempts to craft something tasty and sweet that reflected his philosophy of nourishment, my dinner companion and I began exchanging the glances of people who were being treated to more information than they needed or desired. For this chef, however, food and identity were a matter of principle. Not only did food provide his livelihood, but it defined his struggles as a chef, a businessman and an ambassador of a philosophy about how we should eat. At least in this instance, it also defined his relationship to those around him. Food was intrinsic to his conception of how one should live one's life. He was his food in a way that was even more all encompassing than what Brillat-Savarin (1982) could have imagined when he argued that we are what we eat.

This special issue of PORTAL Journal of Multidisciplinary International Studies focuses on food and Francophone cultures. The cultures of the French speaking world have inherited many of the French traditions about the importance of food and dining, as well as questions about what to eat and drink, how to consume it, and what such practices might reveal about those who make choices about food. When approached to 
contribute to this special issue, the authors found that issues of food were already underlying their research into the literatures and cultures of the Francophone world. This collection of papers thus brings the questions of cultural identity, memory and transculturation that are the mainstays of Francophone Studies into conversation with the matters of edibility and food-related practices. While the papers share a reference to the French language, they concern themselves with a variety of discursive spaces, of categories of social actors and of material and symbolic resources in very different parts of the world. Food is explored both in terms of 'real world' issues and as representation, often simultaneously, which attests to the tremendous value of food for understanding culture and identity.

Bonnie Thomas and Tess Do use food to make sense of histories, both familial and national. Thomas's article, explores the connection between history, memory and food in Maryse Condé's memoir Victoire, les saveurs et les mots and underscores the connection between three generations of women. This analysis reveals how family histories form part of a greater narrative of the Caribbean and that food provides both a literal and figurative vehicle for the reappraisal of history. For Do, food provides a sense of comfort and acts as a means of asserting the existence of a national culture distinct from foreign influences in her reading of the historical Franco-Vietnamese detective novel Les Travers du Docteur Porc. Do challenges the role given to food in crime fiction in order to read food as a way to assert a distinct national identity and a sense of comfort at a time when foreign powers were encroaching on Dai-Viet.

More ambiguous or troubled relationships with food emerge in the essays by Karin Speedy, Amy Hubbell and Angela Giovanangeli. Speedy's analysis of forced and unwitting cannibalism in the oeuvre of New Caledonian writer Georges Beaudoux takes up the European notion of the cannibal as the ultimate Other and uses its particular evocations in Jean M'Barai le pêcheur de tripangs. Following Beaudoux's lead, she queries how cannibalism might be better understood as a trope for the figure of the métis. The role of food in the nostalgic processes of those living in exile is complicated in Amy Hubbell's discussion of the popular culture and literary production of the PiedNoir community in France. Forced to flee their Algerian homeland with the war and the independence movement in the 1960 s, food becomes both a way of connecting with a lost past and a focus for painful remembrances. 
Angela Giovanangeli's paper draws on notions of resistance and social change and investigates some of the recent transformations of food distribution in France. Her case study of a French farm market explores how the local farm market initiative can be viewed as a creative and innovative performance that questions mainstream food practices.

The role of food in the positing of cultural identity is examined in the special issue's last two essays by Jean Anderson and Julie Robert, who find themselves on opposite sides of this debate. Anderson's article examines the way food and eating within the colonial and postcolonial francophone context form a conflicted interface between indigene and coloniser. Anderson draws on a range of fictional texts by Oceanian writers, mainly from the French-speaking Pacific, to reflect on the meaning and function of food in relation to indigenous identity in the face of colonisation and the belief that modernisation will lead to the adoption of metropolitan food practices. For Robert, by contrast, food - as taken up by Shanghai-born Quebecoise author Ying Chen in Le Mangeur - fails to be emblematic of larger cultural or moralistic constructs. Rather, she argues that notions of edibility stem from the food-related choices that flow from our embodiment, thus helping us understand who we are.

Central to this special issue and the question put to all the authors is the matter of how food constructs and reconstructs identity at different periods of time, in different French speaking countries and in different ways. As the papers in this issue attest, it is a question that lends itself to many answers, for as much as food is a common global concern, it is still intensely anchored in localised activity and interactions. Food therefore serves as an ideal way to explore the diversity of experiences and circumstances represented by the common frame of la francophonie.

\section{Reference List}

Brillat-Savarin, J. A. 1982, La Physiologie du goût, Champs classiques, Paris. 